\title{
ANÁLISIS CRÍTICO Del discurso de los "MEMES" ALUSIVOS AL DEBATE SOBRE PARAMILITARISMO DEL CONGRESO DE LA REPÚBLICA DE COLOMBIA (2014) ${ }^{1}$
}

\author{
ANÁLISE DO DISCURSO DOS “MEMES” ALUSIVOS AO DEBATE SOBRE \\ PARA-MILITARISMO DO CONGRESSO DA REPÚBLICA DA COLÔMBIA (2014)
}

SPEECH ANALYSIS OF "MEMES" IN REGARD TO THE PARAMILITARISM DEBATE AT CONGRESS OF THE REPUBLIC OF COLOMBIA (2014)

Por

Francisco González Espinosa

Estudiante de la Licenciatura en Lenguas Extranjeras

francisco.gonzalez@correounivalle.edu.co

\section{Esteban Herrera Vargas}

Estudiante de la Licenciatura en Lenguas Extranjeras esteban.herrera@correounivalle.edu.co

\section{Alfonso Vargas Franco}

Profesor Escuela de Ciencias del Lenguaje alfonso.vargas@correounivalle.edu.co Universidad del Valle, Cali.

Resumen: Este artículo presenta los resultados de un estudio que tuvo como objeto la caracterización retórica de memes alusivos al debate sobre paramilitarismo en el Congreso de la República de Colombia de 2014 desde el análisis del discurso multimodal. En el presente artículo se describirán y analizarán dos de los memes del corpus, que fueron seleccionados por registrar mayor circulación en las redes sociales Facebook y Twitter, y en los que a juicio de los autores, se evidenciaban puntos de vista críticos con las situaciones del debate y las posturas políticas de los personajes involucrados, además de poseer un contenido rico en elementos culturales y visuales para la construcción discursiva y del humor. El análisis permitió concluir que mediante el uso de recursos retóricos y visuales burlescos, estos memes buscaban presentar posicionamientos políticos radicalmente opuestos a través de los discursos centrales del debate, y en especial, exponían las ideologías antagónicas de los senadores enfrentados: Álvaro Uribe e Iván Cepeda. 
Palabras clave: Meme, tecnologías digitales, redes sociales, práctica vernácula, texto multimodal, análisis del discurso, humor.

Abstract: In this article we expose a rhetoric characterization made from multimodal discourse analysis approach, of memes about the debate of paramilitarism taking place in the Congress of Colombia in 2014. The entire corpus was composed by four memes, in this article we describe two of them. All selected memes had the highest circulation on social networks Facebook and Twitter, in which, according to authors' opinion, were found highly critical points of view regarding the incidents in the debate and the attitudes or political background of the characters involved in it, diversity of cultural contents and visuals elements used to produce the discourse and humor. The analysis allowed us to conclude that these memes used rhetorical and burlesque resources to express different political positions to specific events of the debate, and mainly, to explain the antagonistic ideologies of senators faced in the debate: Álvaro Uribe and Ivan Cepeda.

Key words: Meme, digital technology, social networks, vernacular language, multimodal text, discourse analysis, humor.

Resumo: Este artigo apresenta os resultados de um estudo que teve como objetivo a caraterização retórica de memes alusivos ao debate sobre para;militarismo no Congresso da República de Colômbia de 2014, através da análise do discurso multimodal. Neste artigo vão se descrever e analisar dois dos memes do corpus, que forma selecionados porque registraram maior circulação no Facebook e no Twitter. Segundo os autores, estes memes mostram os pontos de vista críticos com respeito às situações do debate e as ideias políticas das personagens involucradas. Além de possuir um conteúdo rico em elementos culturais e visuais para la construção do discurso e do humor. A análise permitiu concluir que por meio do uso de recursos retóricos e visuais cômicos, estes memes visavam apresentar posturas políticas radicalmente opostas através dos discursos centrais do debate. Também, especialmente, expunham ideologias antagônicas dos senadores Álvaro Uribe e Iván Cepeda.

Palavras-chave: Meme, tecnologias digitais, redes sociais, prática vernácula, texto multimodal, análise do discurso, humor.

Reconocemos la necesidad de abordar los memes como nuevas formas de comunicación que emergen en nuestro entorno social. Desde la perspectiva disciplinaria del Análisis del Discurso Multimodal, hemos podido observar que este fenómeno comunicativo que llamamos memes se ha expandido gracias a la masificación de las redes sociales virtuales y a la vertiginosidad digital que permite crear, reproducir y propagar masivamente nueva información. En efecto, estos han adquirido una atención relevante dentro de nuestra actividad cotidiana en internet. Los memes permiten la interacción entre personas por vinculación social particular, o bien para compartir ciertos intereses y gustos personales (como por ejemplo, los trabajadores de una empresa, los estudiantes de una institución, una comunidad cristiana, los amantes de las mascotas, etc.). 
En este trabajo se decidió describir y analizar una muestra de la producción de memes que surgieron alrededor de un importante acontecimiento nacional que tuvo lugar en el Congreso de la República: el debate sobre paramilitarismo en el Senado, realizado el 17 de septiembre de $2014^{2}$. El propósito del estudio es identificar e interpretar los elementos retóricos que generan la construcción del significado en esta nueva forma de codificación, además de explorar su carácter "lúdico-recreativo". Se trata de una práctica vernácula ${ }^{3}$ de escritura multimodal que se desarrolla al margen del normativismo lingüístico y las instituciones educativas, y en muchas ocasiones, como manifestación de resistencia por parte de la ciudadanía a los discursos elaborados por los grupos dominantes a través de los medios de comunicación, el gobierno, la religión, la universidad, la sociedad de consumo, etc.

Sin embargo, para comprender el mecanismo enunciativo del meme en el mundo actual, es conveniente contextualizar en qué dominios de actividad humana cobra vida esta práctica social de comunicación discursiva. El origen de los memes se dio gracias a la integración y desarrollo de las tecnologías digitales y al auge masivo de las redes sociales. En conjunto, estas han producido una transformación súbita de las tecnologías de la información y de la comunicación, cuyo impacto ha afectado a todos los sectores de la economía y de la sociedad. Un cambio sin precedentes del que tal vez no se pueda establecer comparación con ningún otro en toda la historia de la humanidad.

Una de esas transformaciones la estamos viviendo hoy al ver los profundos cambios que se han producido en el lenguaje empleado a través de estas tecnologías. En ellas, solemos expresarnos de la forma más coloquial, tal y como nos comunicamos verbalmente con amigos y familiares, suprimiendo o cambiando fonemas, omitiendo vocablos y haciendo construcciones sintácticas libres. En su forma escrita, el lenguaje digital evidencia todas las mencionadas prácticas vernáculas orales y añade, además, nuevas formas de comunicación discursiva, creando códigos que acortan o simplifican la palabra escrita convencional.

La expansión de las redes digitales ha hecho posible, con un solo clic, el acercamiento de amplios sectores ciudadanos residentes en espacios geográficos muy distantes entre sí. Las fronteras territoriales se han visto superadas por las tecnologías de la información y a diario se transmiten alrededor del mundo ideas políticas, militares, económicas, sociales, empresariales y de toda índole.

La circulación inmediata de todo tipo de información, es ahora mediada por un sinnúmero de dispositivos digitales tan sofisticados que se pueden llevar fácilmente y que cuentan con conexión a internet satelital. Esto nos permite estar informados de forma instantánea sobre cualquier novedad que acontezca, si así lo queremos. Tenemos a la mano smartphones, tablets y PCs constantemente. De hecho, ahora es casi imposible llevar una vida normal sin ellos. Su uso en ámbitos educativos y laborales es imprescindible para muchas de las actividades que exigen, sin mencionar su uso en el campo del entretenimiento. Así mismo, las redes sociales virtuales son accesibles desde cualquiera de los dispositivos ya mencionados. 
En la actualidad, las redes sociales más populares y las que cuentan con la gran mayoría de ciudadanos y entes activos (empresas, instituciones, entre otras) son las redes Facebook y Twitter. Entre ellas se reparten la mayor cantidad de usuarios, más de 1350 millones (según la Wikipedia, consultada el 02-06-2015) alrededor del mundo, y por ende cuentan con la mayor difusión mediática.

Como se observa, la circulación informativa y los procesos tecnológicos que las soportan han generado prácticas sociales modernas como las videollamadas, servicios de mensajería instantánea, blogs, videoconferencias, entre otras, creadas por la actividad humana en medio del avance tecnológico. De modo que la forma en que nos comunicamos a través de esta diversidad de medios también se ha transformado, obedeciendo a las necesidades que estos procesos exigen. Por ejemplo, se reproducen y se generan fenómenos lingüísticos particulares como los de 'escritura simplificada' o escritura ideofonemática (Cassany, 2012).

En definitiva, gracias a las posibilidades comunicativas que ofrecen a los usuarios, estas redes han funcionado como medios para manifestar oposición y resistencia al poder. En las redes sociales convergen comunidades afines o ligadas a cualquier actividad de interés humano, sin ser la excepción comunidades académicas que colaboran de manera conjunta, dando pie a cambios en forma de movilizaciones ciudadanas, apoyándose de forma fundamental en cómo se produce y presenta la información de los acontecimientos noticiosos sociales y políticos. Al ser redes de libre acceso y manejo, la divulgación de hechos o conocimientos informativos es presentada por los usuarios tal y como ellos mismos perciben dichos acontecimientos, es decir, presentan la información libre de "filtros". Según la teoría chomskiana del Modelo de Propaganda (1990), los sucesos presentados por los medios de comunicación oficiales pasan por ciertos filtros antes de ser divulgados, de modo que los discursos y orientación de la información favorezcan las ideologías e intereses de quienes los controlan, regulando así el contenido de lo que se emite.

Los siguientes son los 'filtros' a los que están sometidos los medios de comunicación masiva (Chomsky \& Herman, 1990):

1. En su gran mayoría están en manos de grandes corporaciones, es decir, pertenecen de hecho a las élites económicas.

2. Dependen de la publicidad de las élites económicas para su existencia.

3. Deben producir un flujo permanente de nuevas noticias. Los principales proveedores de noticias son los departamentos de prensa de los Estados o las grandes corporaciones.

4. Los grupos de influencia pueden organizar respuestas sistemáticas ante cualquier desviación sobre las opiniones que sustentan.

5. Inicialmente conocido como filtro Anticomunismo ${ }^{4}$. Las opiniones de izquierda son consideradas como «antipatrióticas». 
Como usuarios de estos nuevos medios de comunicación encontramos frecuentemente hechos y acontecimientos noticiosos recientes con puntos de vista distintos, incluso con aspectos desconocidos por los medios informativos convencionales. Así como lo plantea Vargas Franco (2015), en su artículo sobre Redes Sociales; literacidad e identidades:

En otras palabras, las redes sociales cambian la estructura de construcción y divulgación de los hechos, así como el rol de los protagonistas de los hechos noticiosos. Hoy cualquier usuario anónimo en internet y las redes sociales puede desempeñar, de algún modo, el papel de periodista que hasta el momento ha venido siendo desempeñado como un rol dominante y acrítico en la construcción de la noticia. (pg. 7).

Todo ello pone de manifiesto el poder de convocatoria para las movilizaciones y concentraciones de protesta ciudadana que tienen estas redes virtuales a nivel mundial. Muchas de las que ya hemos sido testigos a partir de su auge a mediados de la primera década del siglo XXI. Para mencionar algunos ejemplos, tenemos la revolución egipcia que tuvo lugar en 2011 y que no hubiera sido tan multitudinaria de no haber sido por el papel de las redes sociales. Otro ejemplo es el movimiento de los indignados en España, tras la crisis económica de 2008.

En nuestro país evidenciamos en el año 2011 las manifestaciones masivas contra la reforma educativa y el apoyo al Paro Agrario, que dejaron como resultado grandes participaciones de la representación estudiantil, en debates de escenarios tan distantes como el Congreso de la República y la conformación de la Mane (Mesa Amplia Nacional Estudiantil) aún vigente.

\section{El meme}

El término meme se originó en la disciplina de la biología y lo propuso el científico teórico evolutivo Richard Dawkins (1976) en su libro El Gen Egoísta. De manera análoga a la transmisión de la información genética, el autor plantea que el meme es la unidad mínima de información de la transmisión cultural, ya que los genes se quedan cortos en explicar ampliamente la evolución cultural y las grandes diferencias culturales que presentan distintos grupos humanos alrededor de todo el mundo.

Al igual que el gen, el meme es una entidad replicadora y se encuentra cotidianamente en la cultura humana. Para Dawkins (1976), esta entidad es fundamental para explicar el proceso evolutivo. Su nombre surge del concepto de imitación; en griego "Mímeme». Este término es abreviado de tal forma que se asemeje más a una palabra simple (en forma) como lo es "gen». Ejemplos rudimentarios de memes podrían ser: tonadas o sones, ideas, consignas, modas en cuanto a vestimenta, formas de fabricar vasijas o de construir objetos. Mientras que el gen se preserva y propaga al saltar de un cuerpo a otro mediante los espermatozoides y los óvulos, el meme se propaga en el acervo de memes al saltar de un cerebro a otro mediante un proceso, que podría llamarse, ampliamente, de imitación. De allí nace el término tomado por el fenómeno lingüístico y discursivo que es objeto de nuestro estudio. 
Los memes, en una larga acepción semiótica dentro del medio informático, y siendo fieles con el concepto original planteado por Dawkins (1976), son ideas, conceptos, situaciones, expresiones y pensamientos en cualquier tipo de medio virtual. Estos pueden ser enlaces, videos, textos, imágenes y todo tipo de construcción multimodal individual y colectiva que resulte entretenida o susceptible de ser difundida en la red a través de foros, imageboards, sitios web y cualquier otro difusor masivo, si su contenido es juzgado por el espectador promedio como bueno, interesante, provocador u original.

La página web neoteo.com afirma que el nacimiento de los memes sucede cuando su contenido no es forzado, pues surgen más por reacción que por invención. Que una imagen se convierta en un meme, es un evento fortuito y no una consecuencia intencionalmente buscada. Actualmente encontramos en la web diferentes páginas que exponen maquetas o plantillas para crear memes: memegenerator o quickmeme, o foreveralone, u no guy, cereal guy, me gusta, entre otros.

De acuerdo con neoteo.com, como todo meme es diferente, el ciclo de vida es aproximado y sujeto a las cualidades de sí mismo y su difusión, pero en general, puede atravesar las siguientes etapas:

- Nacimiento en algún foro, imageboard, etc. a través de una imagen, video o cualquier formato de contenido original que en principio suele ser rechazado por no ser justamente un meme.

- Luego, mediante su recomendación y su reutilización en distintos sitios, se hace una idea o concepto del contenido y se le otorga un significado colectivo (es decir, empieza a significar lo mismo para todos los que lo comparten).

- Se convierte en suceso debido a su replicación y llega a ser meme con todas las letras.

- Cae en el olvido durante un tiempo.

- En algún momento se lo vuelve a revitalizar modificándolo y cumple un nuevo momento de auge y reutilización.

(Neoteo.com. Memes: Qué son y de Dónde salen. Página consultada el día 14-08-2013)

\section{Enfoques teóricos}

Ahora bien, definimos al meme como un conjunto de significantes que conforman un texto, un tipo de discurso enmarcado en una amplia definición que hoy conocemos como Texto Multimodal. A esta denominación se ha podido llegar después de largos años de investigaciones de distintas disciplinas inscritas dentro de la lingüística y que han ido surgiendo según se ha visto la necesidad académica de definir lo que constituye al texto, poniendo en consideración nuevas formas comunicativas (Lingüistica Textual, Textología, la Gramática de Textos, la Gramática del Discurso, el Análisis del Discurso, entre otros). 
La Lingüística Textual buscó distanciarse de teorías más tradicionales que limitaban el estudio al lenguaje verbal y normativo, sin considerar aspectos extralingüísticos como el uso y el contexto que forman parte del significante (texto) y que en consecuencia sesgaba su estudio:

El aspecto visual del discurso a menudo fue omitido (y todavía lo es) en los estudios del discurso. Sin embargo, la disciplina hermana de la lingüística, la semiótica (estudio de los signos), hace hincapié en que un análisis de las dimensiones visuales del discurso resulta indispensable, especialmente en estos tiempos de comunicación multimedial o multimodal. (Van Dijk, 2003, p.28)

El interés de la Semiótica Social, como lo señalan Hodge \& Kress (1988), se centra en el estudio de la semiosis humana que considera la creación de significados como un fenómeno inherentemente social, es decir, producto de la actividad de los individuos de determinada comunidad junto con sus prácticas comunicativas. Es factible reconocer la importancia del contexto cultural en este campo de estudio. Para la Semiótica Social, lo fundamental está en entender cómo los sujetos emplean los materiales provistos por el entorno para producir los significados, y las interpretaciones del discurso, como vemos en el caso de los memes:

Desde el momento en que una cultura ha tomado la decisión de incorporar un determinado material en sus procesos comunicativos, ese material se convierte en parte de los recursos culturales y semióticos de esa cultura y queda disponible para que nosotros construyamos signos. (Kress \& Van Leeuwen, 2001)

La Semiótica Multimodal (Kress, 2005; Kress \& Van Leeuwen, 2001) se ha encargado de estudiar la comunicación contemporánea situando sus cambios en tres áreas fundamentales para la producción del significado: la representación, la difusión y distribución de los mensajes, y la mediación y comunicación (Kress, 2010). Estas áreas corresponden a los cambios culturales y la evolución tecnológica de la sociedad, los cuales en muchas ocasiones resultan motivados recíprocamente. Uno de esos fenómenos, de acuerdo con Kress (2010), ha sido el desplazamiento del libro provocado por la pantalla digital, y en ese sentido, la lógica del modo de la imagen va desplazando, paulatinamente, la lógica de la palabra escrita en libro impreso. En consecuencia, nos encontramos ahora con un complejo conjunto multimodal de signos que constituyen la composición del discurso, y que se deben tener en cuenta al momento de abordarlo. En él intervienen distintos recursos semióticos que obedecen a distintos modos de construir el significado. En otras palabras, abordar el discurso debe dar cuenta de este fenómeno que nos presenta los textos como unidades de sentido que articulan signos compuestos de diversos modos. 
De lo anterior se deduce que las formas tradicionales de lectura y escritura evolucionan en una combinación y reinvención de diferentes herramientas multimodales para comunicar (gestuales, verbales, icónicas, auditivas, colores, dibujos, etc.)

Para llevar a cabo un análisis crítico de textos multimodales, consideramos que el procedimiento más apropiado es el modelo de estratos de Kress \& Van Leeuwen (1996), puesto que es aplicable tanto en el proceso de producción como en el de interpretación del evento semiótico y contempla los contextos en que este se desenvuelve, de modo que el fenómeno comunicativo, en toda su complejidad, se torna aprehensible para quien desconoce la terminología específica utilizada por los estudiosos de la lengua y la comunicación. El hecho de abordar el contexto como sustrato esencial en la articulación y recepción de mensajes semióticos, implica un distanciamiento de las teorías lingüísticas tradicionales, para enmarcarse en un ámbito que desestima la jerarquización de los códigos, pues lo incorpora dentro de un mismo espectro modal.

Estos autores subrayan, a su vez, que uno de los criterios básicos para sus estudios es no tratar la imagen simplemente como 'figura' o 'ilustración', sino como 'sintagma visual’, haciendo una aproximación al estudio del lenguaje escrito. Tal como en la modalidad verbal, la modalidad visual estructura los sentidos por medio de una sintaxis imagética, que se caracteriza por la existencia de una gramática visual, lo suficientemente amplia para aplicarse tanto a un lienzo como a un layout de revista, o al dibujo de tiras o a la organización de diagramas científicos. Esa característica nos lleva, necesariamente, a reflexionar que todas las discusiones sobre leer lo verbal también se van a aplicar a las situaciones que incorporan el estudio de imágenes. Dicho de otro modo, el lenguaje visual no es transparente ni universalmente comprensible, es una construcción cultural.

Adoptamos, además, el Análisis Crítico del Discurso ACD como enfoque fundamental de esta investigación debido a la pertinencia de su propósito como disciplina académica, con responsabilidad social y principios éticos. El análisis se ocupa de la implicancia del uso del lenguaje en conflictos sociales para evidenciar las relaciones de poder y los discursos de la resistencia. Como lo afirma Van Dijk (2003):

El Análisis Crítico del Discurso se centra en los problemas sociales, y en especial en el papel del discurso en la producción y en la reproducción del abuso de poder o de la dominación. Siempre que sea posible, se ocupara de estas cuestiones que sea coherente con los mejores intereses de los grupos dominados. Toma seriamente en consideración las experiencias y las opiniones de los miembros de dichos grupos, y apoya su lucha contra la desigualdad. Es decir, la investigación realizada mediante el ACD combina lo que, de forma tal vez algo pomposa, suele llamarse "solidaridad con los oprimidos" con una actitud de oposición y disidencia contra quienes abusan de los textos y las declaraciones con el fin de establecer, confirmar o legitimar su abuso de poder. A diferencia de otros muchos saberes, el ACD no niega sino que explícitamente define y defiende su propia posición sociopolítica. Es decir, el ACD expresa un sesgo, y está orgulloso de ello. (p. 144) 
Por otro lado, la teoría de enunciación propuesta por Martínez (2005) nos permitirá entender las dinámicas de comunicación en relación con la intención discursiva de los memes que conforman el corpus para el análisis. Como nos presenta Martínez, en la Situación de enunciación o Dinámica enunciativa se convoca el género y a su vez se constituyen sujetos discursivos que crean relaciones diferentes entre ellos:

El Locutor (voz responsable del enunciado), presenta una imagen de sí o de otros en términos de Enunciador(es) a través de un punto de vista asumido (en un texto podemos encontrar más de un punto de vista lo cual significa que podemos encontrar varios Enunciadores), y en relación con una imagen de Interlocutor en términos de Enunciatario, y, el Tema valorizado en términos de Lo Enunciado o Lo Tercero, voz ajena traída de otros momentos de enunciación, de un acontecimiento, un saber o una opinión que se presenta de una cierta manera. (p. 54)

Tenemos entonces los tres componentes de la Situación de enunciación; el Enunciador, el Enunciatario y el Enunciado o Lo Tercero. En nuestro caso centraremos la atención del análisis en la construcción de Lo Tercero (Enunciado), proporcionado por el reconocimiento de los diversos sujetos discursivos nacientes en cada meme.

Para comprender el sentido del enunciado es importante tener en cuenta que este se desarrolla en relaciones dialécticas dinámicas, es decir, en un medio polifónico. Martínez lo explica de la siguiente forma: "para entender el sentido de un enunciado, es necesario identificar la interacción o confrontación de las diferentes voces que aparecen en el enunciado, y de los puntos de vista que en él se presentan” (2005, p. 98). Mediante el enunciado descubriremos y detallaremos el sentido humorístico y la intención discursiva del Locutor, que según su orientación “ironiza, burla, rebaja, minimiza. A través del discurso referido: minimiza, fastidia, provoca, amonesta, denuncia." (Martínez 2005, p. 97 citado en Pérez, Bonfante 2013, p. 61).

En nuestra investigación encontramos la metáfora como la principal figura retórica usada para la creación satírica y burlesca. En relación con ello, de acuerdo con Lakoff y Johnson (2004), citados por Pérez Bonfante (2013):

La metáfora no es solamente una cuestión del lenguaje, es decir, de palabras meramente. Sostenemos que, por el contrario, los procesos del pensamiento humano son en gran medida metafóricos. Esto es lo que queremos decir cuando afirmamos que el sistema conceptual humano está estructurado y se define de una manera metafórica. Las metáforas como expresiones lingüísticas son posibles, precisamente, porque son metáforas en el sistema conceptual de una persona. Así pues, cuando en este libro hablamos de metáforas, tales como UNA DISCUSIÓN ES UNA GUERRA, debe entenderse que metáfora significa concepto metafórico. (p.61) 
Por último, resaltamos la importancia de la Teoría de la Relevancia para el análisis de los memes. Esta perspectiva afirma que para que la comunicación sea posible, el hablante debe tener cierta expectativa sobre la conducta de su interlocutor; en tal medida, la conversación supone ser un acto cooperativo entre sus participantes puesto que cada uno se beneficia cognoscitivamente. Esto quiere decir que cuando nos comunicamos actuamos de forma cooperativa, porque esperamos recibir y dar información "relevante" tanto que modifique o enriquezca nuestro conocimiento del mundo, y "cuantos más efectos cognoscitivos produzca un enunciado, y menos esfuerzo de interpretación exija, más relevante será.” (Sperber \& Wilson citado en Reyes 2007, p. 54):

En nuestro entorno, mantenemos en constante contacto con diversos tipos de enunciados cuya información puede ser fácilmente accesible, sin que represente ningún esfuerzo de procesamiento. En contraste, podemos encontrarnos con información que exija mucho esfuerzo de nuestra mente para ser procesada. Esta última la llamamos información desconectada. Pero además, tenemos un tercer tipo de información; aquella que es totalmente nueva y en adición está muy conectada con nuestro conocimiento previo. La conexión da paso a la inferencia, proceso que provoca una realimentación de la información nueva. Esta información se considera la más relevante, pues produce un efecto de multiplicación, con menos costo de procesamiento.

Según Reyes (2007), los resultados del efecto de multiplicación los llamamos efectos contextuales y se pueden dar de dos formas:

a) la información nueva permite reforzar información ya existente en la memoria.

b) la información nueva contradice o debilita información anterior.

La relevancia de un enunciado también es mensurable. El grado de relevancia se determina por la relación entre los efectos contextuales y el costo de procesamiento. Establecido por una fracción:

$$
\text { Relevancia }=\frac{\text { Efectos Cognoscitivos }}{\text { Efecto de procesamiento }}
$$

Reyes (2007) menciona la importancia que estos dos autores le conceden a la inferencia como proceso fundamental para la interpretación de enunciados. Además postulan como universal el principio de la relevancia por ser de carácter cognoscitivo. Lo que lo convierte en suficiente para explicar la comunicación lingüística, incluyendo todo principio de cooperación y haciendo que todas las máximas conversacionales propuestas anteriormente por Grice (1975) dentro de la Pragmática tomen un carácter superfluo: basta, de acuerdo con Reyes (2007), con el principio de relevancia. Este principio se aplica a todos los actos de habla intencionales, sin excepción, no se puede violar ni romper. Desde luego un hablante podría fracasar en su intento de comunicar algo y en consecuencia no ser relevante, sin embargo, lo importante es que, con su intención, transmita a los interlocutores la presunción de relevancia que ellos esperan de su enunciado, siendo 'la presunción de relevancia' la que determina la interpretación del enunciado. 
Con todos los factores anteriores, en la interpretación entran en juego el papel de la

inferencia y el contexto. De acuerdo con la teoría, entre los participantes del acto comunicativo se figura un contexto como un conjunto de creencias y conocimientos que llamaremos 'premisas', conformadas por variados conjuntos de creencias, saberes científicos, culturales, lingüísticos, económicos, sociales, religiosos, y conocimientos de la situación misma que envuelve a los determinados participantes un acto de habla, en cuyo caso podría ser una historia pasada común entre las partes de la conversación, conocimiento de la personalidad del interlocutor, etc. Es importante tener en cuenta que para la teoría de la relevancia, el contexto se define solo en términos psicológicos, no sociales, ni culturales ni discursivos. "Lo importante es que los interlocutores comparten o creen compartir una versión parecida del contexto. La comunicación exitosa depende de cierto conocimiento mutuo: de lo que cada interlocutor sabe y sabe que el otro sabe" (Reyes 2007, p. 57). De este contexto se extraen las implicaturas de lo dicho. Lo dicho es entendido netamente como lo emitido de forma textual. Las implicaturas son la información implícitamente dada (en lo dicho) a partir de las premisas del contexto. Los hablantes discriminan (por inferencia) las premisas más irrelevantes de las más relevantes para interpretar acertadamente el enunciado y esto lo conocemos como lo comunicado, guiados por los factores de interés implicados en la situación de comunicación, consistente con el principio de relevancia. Así, en esta teoría, lo dicho lo conocemos como la explicatura del enunciado: la proposición completa que expresa el hablante.

Según Sperbery Wilson — continua Reyes (2007) — los hablantes comunicamos pensamientos complejos. En muchos de los enunciados que producen, no se dice la verdad literal con la intención de que los oyentes extraigan solo un subconjunto de implicaturas. En esos casos, no dan garantía de la verdad literal de lo que dicen, sino que su intención es transmitir las implicaturas que consideran relevantes para comunicar a $\mathrm{su}(\mathrm{s})$ interlocutor(es), teniendo en consideración el contexto en que se hallan.

Con relación a las metáforas, esta perspectiva plantea que los enunciados figurados exigen un mayor esfuerzo de procesamiento, no obstante, también producen mayor ganancia cognoscitiva: pues de tan solo un enunciado puede derivarse un significado mucho más complejo que su paráfrasis literal: "Por eso las metáforas e ironías no son adornos de la conversación, sino medios de comunicar gamas muy amplias de implicaturas de diferente rango." (Reyes 2007, p. 63). Asimismo, de acuerdo con esta teoría, su interpretación conlleva el mismo proceso que requiere el lenguaje literal, ya que se rige bajo el mismo principio de la relevancia.

Nuestro análisis, por ende, debe partir de la decodificación del lenguaje de los memes alusivos al debate sobre paramilitarismo de la extracción de las implicaturas más relevantes figuradas por el contexto del debate y de la actualidad nacional y hasta mundial. De este modo se logra una interpretación precisa del significado que hay detrás de cada meme, junto con sus implicaciones políticas y sociales, sus intenciones críticas, satíricas y de denuncia a través del uso del humor como una manifestación de voz libre (libertad de expresión). 


\section{Metodología y corpus}

\section{Objetivos y preguntas de investigación}

El objetivo general de este estudio es analizar y describir, desde el punto de vista del análisis crítico del discurso y la multimodalidad, los memes que hacen referencia al debate sobre paramilitarismo con el fin de caracterizar sus aspectos ideológicos, discursivos, humorísticos y críticos. Los objetivos específicos buscan, en primer lugar, evidenciar qué ideologías y puntos de vista se promueven en estos memes, y en segundo lugar, generalizar, a partir de la muestra analizada, sobre la función del meme como medio de opinión y expresión popular alternativa a los discursos oficiales.

Para este análisis es necesario tomar como base científica el método de investigación cualitativa, conociendo las características del objeto de estudio y los factores presentes en la interacción que se genera alrededor de él. El propósito de la investigación busca comprender en profundidad actos comunicativos que se enmarcan dentro del estudio del comportamiento humano. Para acercarnos a la comprensión de estos actos comunicativos, recurrimos a principios básicos hermenéuticos de investigación como la observación, descripción e interpretación, no del grupo humano, sino del lenguaje empleado por sus miembros, que nos permitirá comprender e interpretar concepciones y puntos de vista de las personas (perspectiva émica).

Se realizaron consultas en internet para la recolección del material que constituye el corpus para analizar: cuatro memes tomados de varias fuentes oficiales como El espectador o El país, y no oficiales como El Pulzo, KienyKe y cuentas personales de Facebook o Twitter.

Con el propósito de obtener una muestra representativa de la cantidad de puntos de vista relevantes expresados en los memes referentes al debate, se escogieron en total cuatro, que abarcaron, según el juicio de los investigadores, gamas muy amplias de implicaturas (mayor ganancia cognoscitiva), incluyendo críticas de mayor peso político o social relacionadas con los temas y hechos puntuales que generó el debate. También se tuvo en cuenta que estos memes presentaban contenido rico en elementos culturales y visuales para la construcción discursiva y del humor

Los criterios para la selección fueron: 1) Clara alusión a las situaciones desarrolladas en el debate sobre paramilitarismo en el Congreso de la República. 2) Enunciado que cumpliera con el principio de 'presunción de relevancia'. 3) Imágenes que tuvieron una alta replicación en las redes sociales Facebook y Twitter. 4) Diversidad de puntos de vista; en lo posible representativa de la cantidad de ideologías o posturas que la totalidad de memes consultados, atacaran o favorecieran. 5) Diversidad de recursos para la composición del meme (retóricos, humorísticos y tipos de imágenes). 


\section{Análisis}

Los memes escogidos fueron sometidos a una descripción de su contexto, es decir, además de estar enmarcados en los sucesos del debate, como se verá en el análisis, cada meme presenta un contexto único determinado por recursos visuales o referencias culturales a las que alude. Después se hizo el análisis discursivo; la interpretación enunciativa, las ideologías que promueven y las críticas que hacen. Se analizó el recurso de la polifonía discursiva empleada en la construcción de ellos. Y por último, se extrajeron los elementos más humorísticos a los que cada meme hace referencia, y se analizaron desde el punto de vista de la burla como estrategia discursiva de resistencia.

Adicionalmente, se presentó cada meme con un correspondiente cuadro referencial, en el que se incluyó la adjudicación de un título general para el meme y se proporcionó información sobre la fecha de creación, fuente que lo produjo o lo divulgó, origen o motivación de su creación y una breve descripción global.

\section{Meme $\mathrm{N}^{\mathrm{o}} 1$}

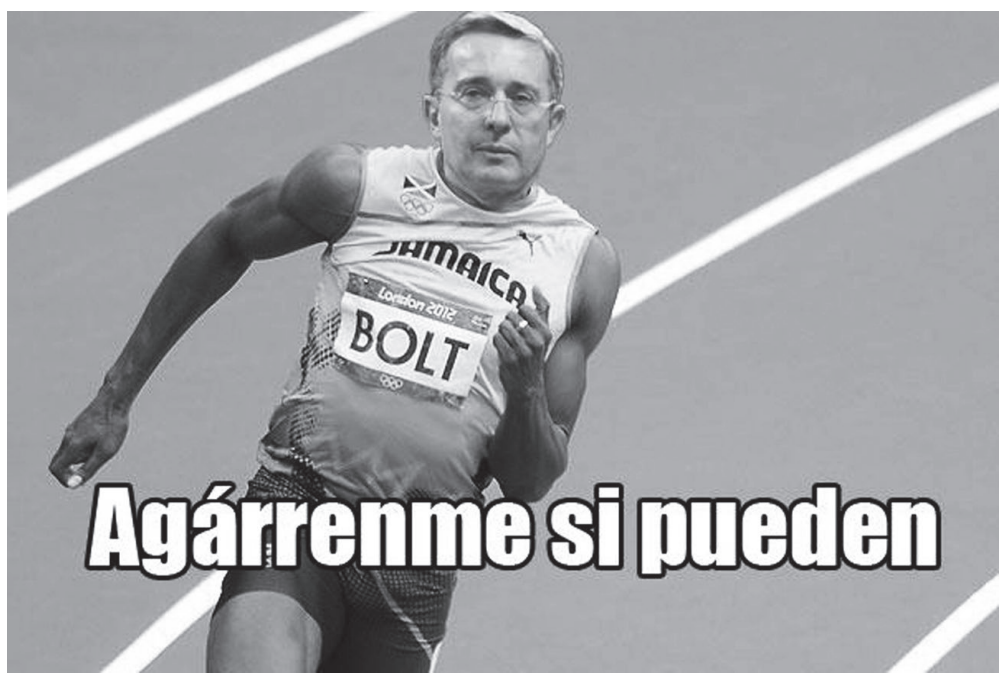

\begin{tabular}{|c|l|}
\hline Título & Uribolt \\
\hline Fecha & Septiembre 2014 \\
\hline Fuente & $\begin{array}{l}\text { http://www.elpais.com.co/elpais / Álvaro-uribe-velez/ } \\
\text { fotos/memes-dejo-candente-debate-control-politico- } \\
\text { contra-Álvaro-uribe }\end{array}$ \\
\hline Origen & $\begin{array}{l}\text { Cien metros planos, Olímpicos Londres 2012, (UsainBolt) } \\
\text { medalla de oro. }\end{array}$ \\
\hline Descripción & $\begin{array}{l}\text { Se hace alusión a cómo el senador Álvaro Uribe huye del } \\
\text { recinto donde se realiza el debate en comparación con el } \\
\text { atleta más rápido del mundo Usain Bolt. }\end{array}$ \\
\hline
\end{tabular}




\section{Contexto y multimodalidad}

Como podemos observar, en este meme se fusionan dos contextos reconocidos, el deportivo y el político. Por una parte, el contexto deportivo lo representa el cuerpo de uno de los atletas jamaiquinos más reconocidos a nivel mundial por sus proezas olímpicas y records mundiales. Por otra parte, se muestra el rostro del expresidente de la República de Colombia Álvaro Uribe, tomando el puesto y profesión del jamaiquino; corriendo sobre la pista.

Dentro de este meme se reconoce un tipo de texto multimodal que puede ser compuesto por imágenes, ilustraciones estáticas, o fotos digitalizadas de figuras humanas, en este caso, la figura de Usain Bolt que ha sido alterada con el rostro del expresidente Álvaro Uribe, con el fin de establecer una relación metafórica. Esto representa una intención de denuncia recurriendo a un gesto de alta carga burlesca en relación con en el contexto colombiano que rodea a la imagen.

En primer lugar, este montaje de imágenes, en conjunto con las palabras, tienen como fin expresar, a través de la ridiculización del personaje, una crítica a la forma como el senador Uribe salió del recinto una vez terminó su intervención en el debate, sin dejar oportunidad de escuchar las réplicas de los demás interlocutores.

En segundo lugar, este meme da cabida a que el espectador pueda vincular la composición gráfica, con la constante mitigación del expresidente y senador Uribe de su propia responsabilidad. Además, este expone una visión satírica frente a la poca efectividad de la justicia en Colombia, más aún cuando el expresidente es cobijado por un fuero especial. Aquello entrevé un debate en torno a acontecimientos políticos donde la impunidad aún sigue siendo la ley. Se observa cómo continúa siendo reiterativo el uso de imágenes alusivas a la evasión de cargos penales por parte del expresidente Uribe.

\section{Análisis del Discurso}

A través del análisis crítico del discurso, puede plantearse que el meme parte de un rechazo a la actitud que muestra el expresidente Álvaro Uribe frente a las acusaciones planteadas por su homólogo en el Congreso Iván Cepeda, en donde, de una forma "olímpica" decide evadir las acusaciones y retirarse del recinto del debate, sin mostrar ningún pudor ni respeto por sus contradictores.

A nivel ideológico dentro del panorama político colombiano, al ser un debate sobre paramilitarismo, se acentúa una polarización política (a favor y en contra del expresidente) en continuo ataque. En este caso, representados por el senador Uribe como aquel que huye de toda culpa o señalamiento. En el meme, también se puede admitir una reacción de denuncia por parte del autor, a través de la metáfora se esboza otra implicatura: un señalamiento claro en contra del senador Uribe, pues es representado al nivel de un velocista, pero que a diferencia del deportista, compite por ser el más rápido en huir de las acusaciones sobre paramilitarismo y abuso de poder que se le imputan. Es una escena caricaturizada como una fuga. 


\section{Polifonía del discurso}

En el mensaje literal podemos leer "Agárrenme si pueden", con ello el emisor promulga la implicatura más importante del meme: el acto cobarde del senador y además deja entrever una postura en contra del personaje montado sobre la imagen del deportista (Uribe sobre UsainBolt) de donde se desprenden otras implicaturas relevantes, ya que de alguna manera el expresidente Uribe siempre evade entrevistas y procesos tanto políticos como legales que cuestionan sus acciones, la justicia es incapaz de condenarlo. Aquí encontramos un juego de voces muy interesante de acuerdo con Bajtín (2005), puesto que la parodia constituye un acto profundamente polifónico, al convocar tanto la voz de poder que se está parodiando (en nuestro caso la de Uribe), como la voz del burlador (Bolt), evidenciada en la implicatura principal del enunciado ya mencionada. Otro mensaje contundente que el emisor puede sugerir, es cómo en un país como Colombia, una persona puede ser "inalcanzable" en términos político-jurídicos. De esta manera el Meme $\mathrm{N}^{\circ} 1$ da cabida a sus intérpretes en las redes sociales, a pensar cómo aun los denunciantes y personas en contra de las acciones del ex mandatario se ven incapaces e impotentes frente a todo su despliegue político que produjo una gran cantidad crímenes y desapariciones.

\section{Humor}

Por una parte, se alude a contrastar la capacidad atlética de uno de los deportistas más emblemáticos a nivel mundial Usain Bolt, con sus irrompibles records de velocidad tanto en Olímpicos como competiciones mundialistas, hasta ahora considerado el hombre más rápido del planeta, con la forma de proceder de un representante político colombiano. Esta mixtura de contextos distantes entre sí produce un efecto altamente humorístico.

Igualmente, a través de este meme podemos identificar el uso de la metonimia, una relación metafórica que consiste en un tipo de analogía o asociación entre elementos a los que se les establece alguna similitud en el significado, para sustituir a uno por el otro, en una misma estructura. En este meme, el político con la huida más rápida de un recinto del Congreso de la República (Uribe), toma el nombre del corredor más rápido del mundo (Bolt). Relación en la que también podemos encontrar una expresión hiperbólica de la agilidad con la que Uribe desertó del debate. En este caso la intención discursiva del locutor es de denunciar y ridiculizar el acto del senador Uribe, abandonar el recinto tras las acusaciones emitidas por el senador Cepeda. 


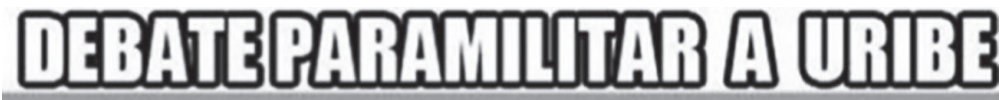

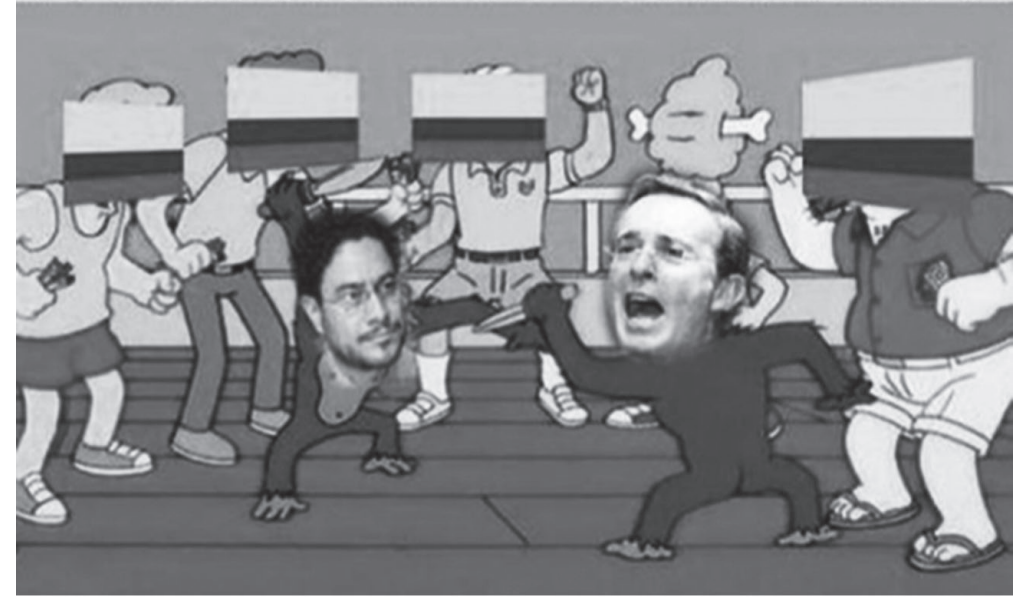

\begin{tabular}{|c|l|}
\hline Título & ¡Uribe y Cepeda a muerte! \\
\hline Fecha & Septiembre 2014 \\
\hline \multirow{2}{*}{ Fuente } & $\begin{array}{l}\text { http://www.elpais.com.co/elpais/Álvaro-uribe-velez/ } \\
\text { fotos/memes-dejo-candente-debate-control-politico- } \\
\text { contra-Álvaro-uribe }\end{array}$ \\
\hline \multirow{2}{*}{ Origen } & $\begin{array}{l}\text { Capítulo 12 de la temporada 11, The Simpson } \\
\text { (La Familia Mansión) }\end{array}$ \\
\hline \multirow{2}{*}{ Descripción } & $\begin{array}{l}\text { Recreación de una escena de la famosa serie animada de los } \\
\text { Estados Unidos The Simpsons (Temporada 11 - La Familia } \\
\text { Mansión. Capítulo 12). Donde es combinada de manera } \\
\text { humorística y satírica “el duelo a muerte” entre Álvaro Uribe } \\
\text { e Iván Cepeda durante el debate sobre el paramilitarismo. }\end{array}$ \\
\hline
\end{tabular}

\section{Contexto y multimodalidad}

En este Meme $\mathrm{N}^{\circ} 2$ se puede observar cómo el juego de imágenes montadas unas sobre otras, acompañadas de un título (DEBATE PARAMILITAR A URIBE) nos adentra en dos ámbitos distintos pero con una idea en común: una lucha. En el Meme $\mathrm{N}^{\circ} 2$ son mezclados dos contextos distintos. El primero, es la famosa serie americana de televisión Los Simpsons, que se caracteriza por emplear un sentido del humor sarcástico, como visión autocrítica de la sociedad estadounidense y sus problemas sociales, económicos, religiosos, políticos, etc. El segundo, es el debate sobre paramilitarismo Iván Cepeda versus Uribe. La disputa entre la verdad de uno contra la verdad del otro, se intenta reflejar en los dos simios que sostienen un cuchillo en su mano, y alrededor de ellos, el público con la bandera de Colombia en lugar de los rostros, simbolizando al 
pueblo que se encuentra apostando por cuál de los dos simios prevalecerá, y cual será derrotado. En otras palabras, primará la impunidad o la justicia, cada una representada alternamente en los personajes principales del debate, obedeciendo a la opinión política personal del enunciatario.

En este caso, es utilizado un momento de la serie animada de la cadena Fox, en que sus personajes se encuentran presenciando una pelea ilegal de monos armados con puñales, apostando y arengando activamente por su favorito. Para la composición del meme, sobreponen la bandera de Colombia encima de los rostros de los personajes "humanos" que componen la imagen, y en la mitad, las cabezas de los dos primates en contienda son sustituidas por los rostros de Iván Cepeda y Álvaro Uribe.

Esto puede interpretarse como un uso satírico y de crítica frente al debate que los colombianos estaban esperando. En términos 'bajtinianos', en el carnaval popular, una de las estrategias para la construcción del humor burlesco es parodiar los actos propios de poder, sometiéndolos a una inversión de sentidos; al contrario de exaltarlos, degradarlos (Bajtín, 2005). En este discurso, vemos un acto de poder como lo es un debate del Congreso de la República, degradado al nivel de una lucha "a cuchillo" entre dos monos. Adicionalmente, incluido en la misma representación, se pretende degradar las figuras de autoridad de dos "ilustres" senadores, quienes gozan de tener educación calificada, excelentes modales y comportamientos civilizados.

Simultáneamente se resalta de forma contundente el duelo "a muerte" que tienen estos dos senadores, quienes además personifican ideologías políticas antagónicas, uno que lucha por hacer conocer su verdad y otro que busca quedar libre de cualquier imputación en temas delictivos.

\section{Análisis Del Discurso}

De igual manera que en el otro meme, en este se reconoce el discurso de resistencia por parte de la comunidad ciudadana (usuarios en las redes sociales), a los discursos manejados por los estamentos oficiales de autoridad en nuestra sociedad, como veremos a continuación.

Deducimos que la principal implicatura del meme tiene la intención de demostrar, a través de la parodia, el ocio y amarillismo en muchos colombianos de cara a la disputa de estos dos reconocidos senadores de la República. A lo que además se suma la analogía de representar el suceso como un show mediático, donde se pretende exhibir las disputas del expresidente Uribe versus el senador Cepeda de manera salvaje y animalizada. Este aspecto evidencia la inversión simbólica 'carnavalesca' de estas figuras de poder. La parodia de la lucha de simios simboliza una degradación del ser humano siendo llevado a exteriorizar la parte más primitiva de su condición. La imagen pública de los dos senadores es entonces representada de forma opuesta a las características que como funcionarios ostentan en el imaginario público; la de ser personas civilizadas y diplomáticas ante los conflictos. 
Por otro lado, este meme tiene reacciones divididas, ya que no está claro qué postura toma: a favor o en contra de alguno de los senadores. De alguna manera, se puede considerar como "neutral", en el sentido que no insinúa una inclinación indiscutible de crítica a alguno de los dos senadores o a ideologías políticas que estos representen, tampoco se infieren indicios de apoyar alguna ideología política en particular, sin embargo, sí se expresa de forma clara, la oposición a la parafernalia "política" del debate, el repudio general por todo el acontecimiento y a la forma como este se tornó en la disputa por afecciones personales e ideológicas que demuestran la polarización que ha existido en el país desde el Gobierno Uribe.

Finalmente, como implicatura relevante de la metáfora, se destaca a fondo la crítica al morbo que motiva a los colombianos a presenciar el debate, completando el circo político (o show mediático) montado por los medios, atrayendo la atención general a eventuales sucesos de confrontación como este, pero sin que de ellos trascienda un seguimiento de la información con carácter de responsabilidad ciudadana por parte de sus espectadores.

\section{Polifonía del discurso}

En el Meme $\mathrm{N}^{\circ} 2$ podemos encontrar una diversidad de mensajes tanto directos como indirectos. Un conjunto de posibles voces de este meme, son los personajes que rodean a los dos monos con los rostros de Uribe y Cepeda, que se entienden como la representación del pueblo colombiano, y que en su totalidad, se pueden hallar opiniones y posturas ideológicas divididas, donde de alguna manera, siempre hay interés por apostar a la mejor opción de acuerdo con la convicción política de cada individuo. Sin embargo, en contraparte al debate, la gente siempre demuestra un interés por ver como se "matan" ambos senadores, a través de las afirmaciones y acusaciones mutuas; hecho que corresponde a la demanda del "espectáculo" orquestado por los medios de comunicación y la opinión pública.

En la inscripción textual del meme leemos en letras mayúsculas: "DEBATE PARAMILITAR A URIBE", que cumple la función de título de la escena que la composición de imágenes nos representa. Además este título contextualiza puntualmente en el acontecimiento real al que pretende aludir.

\section{Humor}

En este meme se identifica una metáfora, de las discusiones que siempre han tenido los senadores Iván Cepeda y Álvaro Uribe, y que, por supuesto, se llevaron a cabo en el debate sobre paramilitarismo. 
La disputa a muerte entre los dos senadores mencionados anteriormente y un pueblo que busca saciar su "morbo" frente al enfrentamiento a puñal, simbolizando así una disputa primitiva en la que se apela a los instintos humanos más básicos para imponer la verdad propia en un debate. De esta parodia del acto público, se puede inferir que el locutor toma una postura neutral respecto a los dos senadores. La intención principal recae completamente en satirizar todo el acontecimiento con la analogía de los monos enfrentándose a muerte. Mediante la guerra salvaje de primates, el autor de este meme explota el carácter hostil que siempre ha existido entre los dos senadores, por razones ampliamente conocidas. Ambos son víctimas del conflicto armado colombiano desde bandos casi opuestos, y del que ninguno ha logrado resarcir el dolor. Cabe hacer una breve mención de dichas razones:

Iván Cepeda Castro es hijo del Representante a la Cámara Manuel Cepeda Vargas durante el año 1994 (año en que fue asesinado). En dicha época, Manuel Cepeda es uno de los máximos dirigentes del Partido Comunista Colombiano (PCC) y miembro activo de la Unión Patriótica (UP) partido político. Siendo este último grupo fundado legalmente como propuesta política gracias a la alianza de frentes desmovilizados de varios grupos guerrilleros incluyendo a las $F A R C$, conformado posterior a diálogos y acuerdos de paz con el gobierno. El activismo y pensamiento político popular de este dirigente resultó ser el motivo para que el Ejército Nacional, en alianza con grupos paramilitares, lo asesinaran. En contraparte, el señor Alberto Uribe Sierra, padre de Álvaro Uribe, fue asesinado a manos de guerrilleros de las FARC en un cruce de disparos que tuvo lugar en la hacienda que pertenecía al señor Alberto Uribe y cuyos motivos y sucesos no son aún del todo claros. La acepción más admitida sugiere que los insurgentes tenían intenciones de extorsionar al hacendado (según venía haciéndose una práctica común en la zona); en respuesta defensiva las víctimas abrieron fuego en contra de sus victimarios, resultando muerto el padre del actual senador. Este hecho marcó un precedente en la vida del expresidente y orientó sus propósitos de combatir bélicamente a las guerrillas, conformando grupos como las Convivir, de los que se presume se derivaron grupos armados ilegales de Autodefensas (AUC) y posteriormente grupos paramilitares. Estos dos acontecimientos forjaron las carreras y las luchas políticas de los dos senadores hoy en día enfrentados.

\section{Análisis de resultados}

Aclaramos a los lectores que por motivos de extensión del artículo, tan solo se presentó el análisis de dos de los cuatro memes que hicieron parte del estudio más amplio. Sin embargo, para el presente apartado y las conclusiones, además de los dos memes presentados en este artículo, tendremos en consideración los resultados del análisis de los dos memes adicionales que integraron el corpus completo de la investigación. 
Uno de nuestros principales criterios de selección de los memes a analizar fue su nivel de replicación en las redes. Esto quiere decir que los cuatro memes referentes al debate sobre paramilitarismo, fueron algunos de los más replicados y con más reacciones producidas en las redes sociales y portales consultados. Del análisis podemos extraer las siguientes conclusiones:

\section{El humor}

En los memes analizados, observamos que comparten la intención de provocar risa en el espectador, aspecto del que podemos decir, es el propósito más básico y común de ellos, puesto que es la motivación que los precede a todos. La intención de hacer reír es el motivo de su creación, aun si posterior a su creación, los resultados no son los esperados y el meme no logra causar ninguna gracia.

Tal y como se plantea en la Teoría de la relevancia, podría afirmarse que uno de los principios de relevancia de todo meme, es su componente humorístico, que determina su éxito de replicación. La capacidad humorística de un meme se refleja proporcionalmente en su nivel de replicación en las redes sociales, es decir, su carácter cómico se puede medir en su rango de difusión. Sin embargo, podemos encontrar que si bien un meme muy replicado no causa mucha gracia, tiene implicaturas muy relevantes a nivel crítico, por lo tanto, contiene una gran ganancia cognoscitiva, lo que en consecuencia también refleja en qué medida se difunde.

En cuanto a su composición, notamos que los memes recurrían a emplear recursos muy diversos. Las imágenes y los temas para construir la narrativa provenían de diferentes ámbitos de nuestra sociedad moderna, como programas de entretenimiento de la televisión, el deporte mundial y la publicidad. Todos muy actuales o vigentes en la memoria de una gran mayoría de usuarios de las redes virtuales. De igual manera que los recursos discursivos, casualmente se presentó el uso de figuras retóricas distintas en cada uno de los memes analizados, tales como la perífrasis, la hipérbole, la metáfora, la sinécdoque, el sarcasmo o la ironía. En conjunto, la combinación de estos elementos funcionó de forma adecuada en la construcción de enunciados humorísticos o críticos muy efectivos.

Encontramos además que a través de la burla se expresan los rasgos de la naturaleza de nuestras prácticas y mentalidades, reafirmándolas en la aceptación y replicación del meme, que su vez genera una identidad colectiva de pensamientos. Esto quiere decir que aquellas personas que replican el meme, comparten o están de acuerdo con la visión sugerida por su enunciado, salvo aquellos que lo hagan para rebatirlo o poner en tela de juicio dicha visión, en cuyo caso, estarían cayendo en el juego del debate, de la réplica, incentivando el intercambio de opiniones, que es generado a partir de este nuevo fenómeno. Hallamos esta forma de producir la burla como método estratégico para hacer catarsis, pues en los memes están grabados nuestros valores y prejuicios a modo de expiación. 


\section{Análisis del Discurso}

Desde el punto de vista de su contenido, observamos que ninguno de ellos iba en contra de la imagen del senador Cepeda, tres en contra de la imagen de Uribe, y uno que catalogamos como "neutral" (Meme $\left.\mathbf{N}^{\mathbf{0}} 2\right)$.

\section{Tabla 1.}

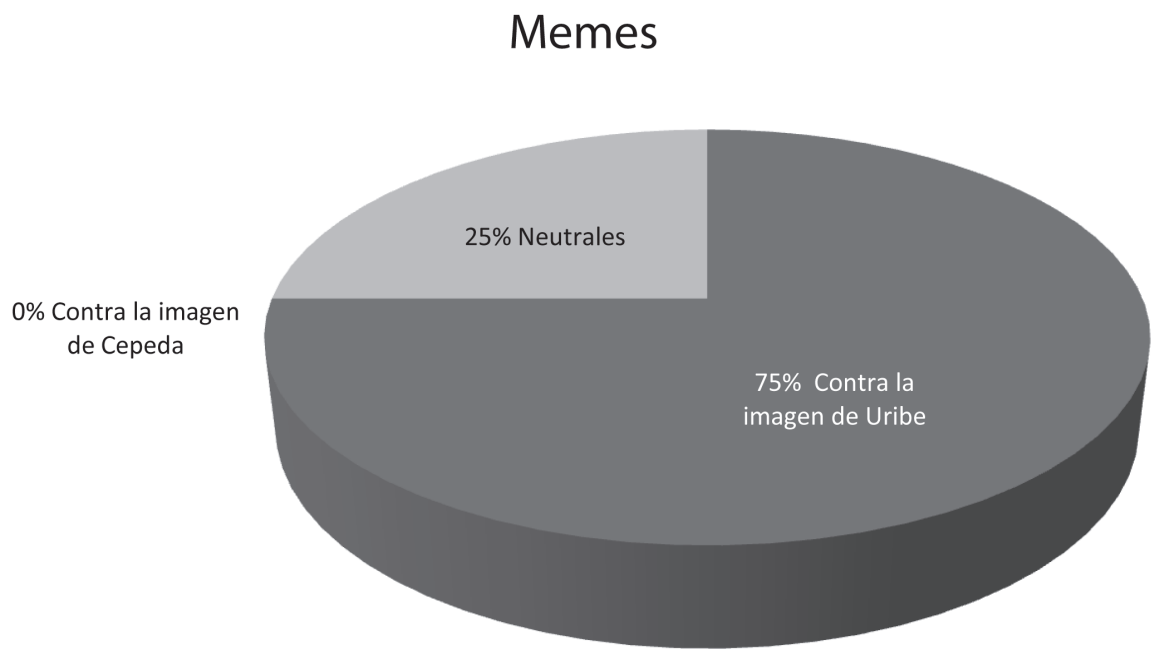

- Cabe resaltar, que de todos los memes que vimos antes de seleccionar los del corpus para el análisis, ninguno buscaba criticar la postura o la imagen del senador Cepeda, en su mayoría juzgaban las actitudes e imagen del senador Uribe.

90 De acuerdo con lo anterior, deducimos entonces que la muestra seleccionada para el análisis es representativa con relación a la proporción de la orientación ideológica de los memes que surgieron alrededor del debate sobre paramilitarismo en el Congreso de la República.

\section{Conclusiones}

$\mathrm{Al}$ analizar los resultados apreciamos una clara tendencia hacia puntos de vista que critican las acciones del senador Uribe. Es evidente que los memes, en su mayoría, fueron utilizados como instrumento para sentar opiniones de oposición a Uribe, en especial al hecho irrespetuoso de haber huido repentinamente del debate una vez terminara su intervención de réplica a la primera exposición realizada por Cepeda. Fue un acto irreverente y soberbio, imitado además por muchos de sus copartidarios del Centro Democrático. Hecho que fue tomado muy ligeramente por los principales medios de comunicación privados masivos del país, en particular los televisivos, que son casi la única fuente de información de gran parte de la población en Colombia. 
Por lo tanto, afirmamos que el meme se ratifica como medio de expresión alternativo a los discursos hegemónicos impuestos por los medios manipulados por o al servicio de las instituciones de poder. Una voz de resistencia que a su vez puede cumplir una función como fuente de información alterna o complementaria, ya que suele ofrecer una mirada creativa (a través de la sátira o parodia) de sucesos comunes enmarcados en ámbitos muy formales y poco susceptibles de ser percibidos de forma jovial, como es el caso del debate sobre paramilitarismo. Lo que también da pie a que el interlocutor reflexione, extraiga o proponga interpretaciones adicionales a las concebidas por el enunciado del meme. O bien, lo induce a hacer reflexiones que refuten aquellas implicaturas que sugiere el enunciado.

Como vemos, el fenómeno de los memes genera una discusión constante alrededor de los temas que los motivan, provocando, entre aquellos interlocutores que asumen la tarea (de forma consciente o inconsciente) de desglosar el mensaje de un determinado meme, un ejercicio de participación "activa" en dichos temas, ya sean de interés local, nacional o mundial.

Actualmente, gracias a la velocidad de la información, en parte impulsada por las mismas redes, presenciamos a diario noticias y eventos de interés general, todos ellos vulnerables a ser juzgados a través de los memes. En este punto, lo notable es que el meme se posiciona como un importante recurso discursivo para emitir una opinión crítica o simplemente una emoción respecto a un tema o hecho. Cualquier persona con acceso a internet y un conocimiento básico en funcionamiento de páginas web, se encuentra en capacidad de producir y publicar un meme. Es un medio de expresión, y como tal, es un medio liberador, de hacer saber a las demás personas lo que sea que en él quiera declararse, sin censura ni voces de autoridad que lo regulen. Y que por su carácter multimodal, facilita la integración de elementos paralingüísticos y extralingüísticos para optimizar la intención comunicativa del enunciado, ampliando la posibilidad pragmática de aludir a muchos conceptos mediante la utilización de símbolos, iconos, gestos, etc. Trayendo de esta forma una interesante creación de referencias intertextuales dentro de los memes, en tanto que enriquece su capacidad dialógica y de comunicar.

Concluimos finalmente que en la actualidad nos encontramos con que los memes son una práctica discursiva multimodal emergente, cada vez más cotidiana y cercana a todos los que están en contacto con el internet. Ha ido ganando espacio y sus efectos sociales le han procurado gran relevancia como objeto de atención en muchas esferas de la sociedad. Por ejemplo, ahora los memes están siendo objeto de investigaciones académicas desde áreas como las ciencias sociales y disciplinas como la lingüística. Además, cuentan con cubrimiento especial de medios de comunicación reconocidos en su formato virtual como El Espectador, Revista Semana, El Pulzo y otros sitios web de información, en los que hacen una recopilación de memes cuando un suceso de interés público genera una producción abundante de ellos.

El tiempo y la tecnología nos mostrarán la evolución de este fenómeno que ha causado gran impacto social a nivel mundial. 


\section{Notas}

${ }^{1}$ Artículo resultado del trabajo de grado para optar el título de Licenciado en Lenguas Extranjeras, Escuela de Ciencias del Lenguaje, Universidad del Valle.

${ }^{2}$ El debate fue promovido por el senador Iván Cepeda con el propósito de denunciar lo que a su juicio son los vínculos del expresidente y hoy senador, Álvaro Uribe Vélez con el fenómeno del paramilitarismo en Colombia. Según Cepeda, Uribe Vélez promovió el paramilitarismo desde que ocupó el cargo de gobernador de Antioquia y se rodeó de terratenientes, banqueros y otros miembros de las élites que financiaban grupos de extrema derecha encargados de ordenar asesinatos selectivos y masacres contra personas que, según ellos, apoyaban a las guerrillas.

${ }^{3}$ Las prácticas letradas se distribuyen por dominios o ámbitos, vinculados a instituciones: la educación (escuelas, institutos, universidades), el gobierno, la justicia, la información, la sanidad, etc. Las Prácticas Letradas Vernáculas son aquellas que existen en un ámbito no vinculado a instituciones formalmente establecidas: lo personal/familiar/amistades, lo privado, lo cotidiano, etc. (Cassany, D. Simposio: 2008. Prácticas letradas vernáculas: análisis y aplicaciones. México: Ríos de tinta).

${ }^{4}$ En el tiempo que se producía esta obra, se vivía la Guerra Fría, motivo por el que proliferaba la propaganda anticomunista en los medios. En la actualidad, podría considerarse comparable a la campaña mundial “antiterrorista” y el desprestigio de movimientos populares civiles que no sirvan a los intereses económicos o políticos de quienes controlan dichos medios. 


\section{Referencias}

Bajtín, M. (2005). La cultura popular en la edad media y en el renacimiento. El contexto de François Rabelais. Madrid: Alianza.

Cassany, D. (2012). En-línea- Leer y escribir en la red. Barcelona: Anagrama.

Cassany, D. (2012). Idioma MSN. Revista Escuela. España.

Cassany, D. \& Hernández, D. (2012). ¿Internet: 1; Escuela: 0?. CPU-e, Revista de Investigación Educativa, 14. Universidad Veracruzana. Veracruz.

Chomsky, N. \& Herman, E. (1990): Los guardianes de la libertad. Traducción de Carme Castells. Grijalbo Mondadori, Barcelona.

Grice, H.P. (1975). "Logic and Conversation,” Syntax and Semantics. Londres: Academic press.

Hodge, R. \& Kress, G. (1988). Social Semiotics. Cambridge: Polity

Kress, G. \& Van Leeuwen, T. (1996). Reading images, the grammar of visual design. London: Routledge.

Kress, G. \& Van Leeuwen, T. (2001).Multimodal discourse. The modes and media of contemporary communication. Londres: Arnold.

Kress, G. (2005). El alfabetismo en la era de los nuevos medios de comunicación. Granada: Ediciones El AljibeEnseñanza Abierta de Andalucía.

Kress, G. (2010). Multimodality:A Social Semiotic Approach to Contemporary Communication. London: Routledge.

Lakoff, G. y Johnson, M. (2004). Metáforas de la vida cotidiana. Madrid: Ariel.

Martínez, M. (2005). La construcción del proceso argumentativo en el discurso: Perspectivas teóricas y trabajos prácticos. Cali: Universidad del Valle.

Pérez, F. (2013). La burla como estrategia discursiva de resistencia frente al proyecto de reforma a la ley 30 de educación superior. Tesis de Maestría. Universidad del Valle. Cali.

Reyes, G. (2007). El abecé de la pragmática. Madrid: Arco Libros.

Richard Dawkins (1976). El Gen Egoísta. Salvat Ciencia.

Sperber, D. \& Wilson, D. (1986). Relevance: Communication and Cognition. Oxford: Blackwell

Van Dijk, T. A. (2000). El discurso como interacción social. Estudios sobre el discurso II. Una introducción multidisciplinaria. Barcelona: Gedisa

Van Dijk, T. A. (2003). Ideología y discurso. Barcelona: Gedisa.

Van Dijk, T. A. (2003). La multidisciplinariedad del análisis crítico del discurso: un alegato a favor de la diversidad. En: Métodos de análisis crítico del discurso.

Vargas Franco, A. (2015). Redes sociales, literacidad e identidad (es): el caso de Facebook. Artículo no publicado. Memes: Qué son y de Dónde salen. (11-08-2011) .Recuperado de: http://www.neoteo.com/memes-queson-y-de-donde-salen-24224/

Recibido: septiembre 30 / Aprobado: noviembre 30 de 2015 